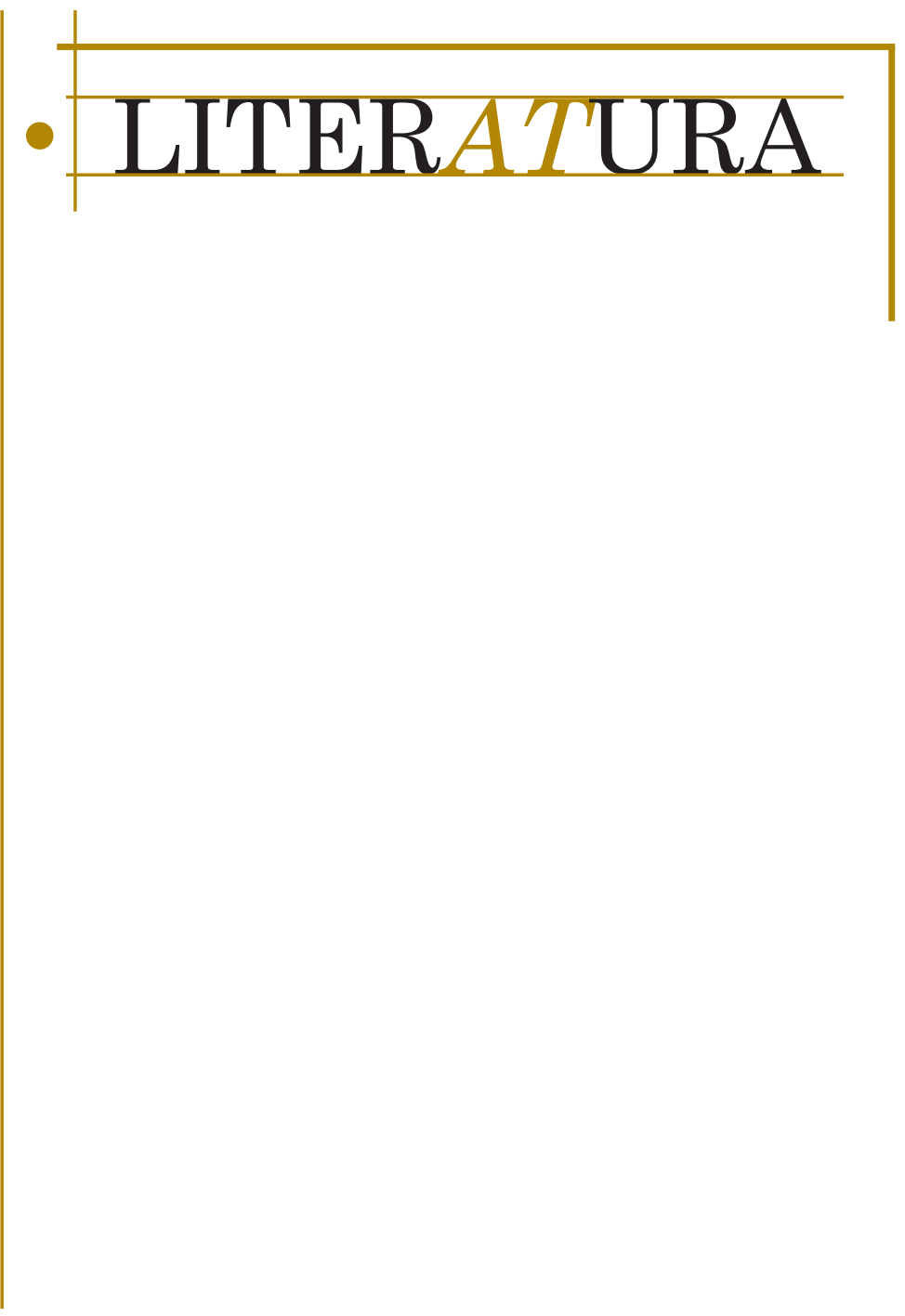




\section{AUTORREFLEXIVIDADE EM CÓPIA FIEL, DE ABBAS KiAROSTAMI}

\section{Genilda Azerēdo*}

Resumo: Propomos a discussão do filme Cópia fiel, de Abbas Kiarostami, a partir da observação de algumas premissas: a narrativa articula ambiguamente as nuances semânticas da expressão "cópia fiel" no nível artístico e no das relações humanas; a narrativa investe substancialmente em estratégias estilísticas, a exemplo da descontinuidade e do paralelismo, que encharcam a história de incerteza, indeterminação e ambiguidade. O filme desloca as noções de autenticidade e cópia do contexto artístico (mimese) para o da subjetividade humana e, ao fazê-lo, desafia e desestabiliza o espectador em sua tentativa de interpretação. Em Cópia fiel, por conta do jogo metaficcional, somos o tempo todo impelidos a refletir criticamente, a tirar rendimento estético daquilo que não se mostra e não se diz, mas constitui-se fundamental para os significados do filme.

Palavras-chave: Mimese. Ambiguidade. Metaficção.

\section{INTRODUÇÃO}

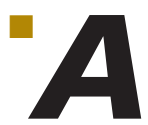

filmografia de Abbas Kiarostami possui uma marca metalinguística e metaficcional acentuada. Citemos, inicialmente, dois exemplos: em Através das oliveiras (1994), temos como argumento central o processo de realização de um filme, com a presença da equipe de filmagem, seleção de atores dentre os moradores da região escolhida como locação, repetição de cenas, enfim, fragmentos da encenação e tentativa de construção do filme. É interessante ressaltar o envolvimento dos moradores, inclusive adolescentes, na própria construção do cenário, ao trazerem jarros de plantas e flores para enfeitar o espaço externo da casa. Tudo parece precário e improvisado. Imiscuído a esse nível metaficcional, em que estratégias de descontinuidade e frag- 
mentação dão a tônica, a narrativa fílmica maior (que contém o filme-menor-em-construção) denuncia problemáticas cruciais da sociedade iraniana, como o analfabetismo, a autoridade dos mais velhos nas decisões de vida dos mais jovens, a relação de poder entre homens e mulheres, a pobreza e o efeito disso nas relações humanas e afetivas.

A sequência final de Gosto de cereja (1997) constitui um epílogo que parece despregar-se do restante da narrativa, ao dar visibilidade à equipe de filmagem, aos equipamentos, inserindo as instruções do diretor e mostrando os atores em ações que não se alinham com as ações que vinham sendo representadas anteriormente, ainda mais quando consideramos a sombria questão do suicídio pairando ao longo do filme. No entanto, tudo é ficção, cabendo a nós, espectadores, apenas distinguir entre seus diferentes niveis diegéticos.

Segundo os teóricos da metalinguagem e da metaficção, a exemplo de Linda Hutcheon, Mark Currie e Patricia Waugh, ao chamar a atenção para o código e a condição de artificio que permeiam a construção de um objeto estético (fotografia, pintura, poema, romance, peça teatral, conto ou filme), o artista explicita a relação problemática entre vida e ficção, lembrando ao leitor/espectador que não apenas a ficção é ficção, mas aquilo que supomos ser "real" também é afetado por representações discursivas e diferentes modos subjetivos de compreensão (WAUGH, 1984, p. 3-4). Além disso, como nos lembra Robert Stam (1981, p. 26), a arte anti -ilusionista, ao proclamar sua própria artificialidade, através de estratégias metalinguísticas e metaficcionais, "traz consigo uma crítica implícita à sociedade que alimenta suas próprias ilusões”, e, desse modo, contribui para desestabilizar posicionamentos de conforto e plenitude proporcionados ao leitor/espectador pelas narrativas tradicionais, que têm como princípio a verossimilhança realista.

Kiarostami atinge um grau sofisticado de utilização de recursos autorreflexivos em Cópia fiel (2010), filme situado fora do Irã, com Juliette Binoche, William Shimmel e Jean-Claude Carriére no elenco. O título Cópia fiel indicia uma série de sentidos ligados à relação entre objeto artístico e reprodução. As expressões Copie conforme, Certified copy e Cópia autenticada, outras variáveis de significado do título presentes na narrativa, acrescentam as noções de autenticidade e garantia, quanto à veracidade da cópia, ao sentido inicial de fidelidade. Inicialmente, quando consideramos apenas o título, é quase impossivel não nos lembrar de Walter Benjamin e sua famosa discussão sobre a obra de arte na era da reprodução técnica e mecânica. Perguntamo-nos se o filme constituirá um filme-ensaio, ao modo de um documentário, em que tal questão será abordada teoricamente.

Quando assistimos ao filme e tentamos apreender o significado de "cópia fiel" de forma contextualizada, isto é, inserido dentro do significado maior da narrativa filmica, a expressão ganha contornos e nuanças que abarcam questões teóricocríticas e experiências de vida: cópia é imitação, encenação, faz de conta; cópia também é mimese, representação, potência criativa. O filme aproveita tal duplicidade para tecer uma narrativa que nunca perde de vista a relação entre arte e vida; e entre arte e arte - criando, portanto, uma articulação interartes. Na verdade, é exatamente a imbricação entre os significados de mimese como representação artística e mimese como representação social que constitui o ponto fulcral do filme. Nesse sentido, também podemos definir esse filme de Kiarostami como metalinguístico, ou mais precisamente, metaficcional, uma vez que sua construção é saturada de recursos que ressaltam a própria noção de representação e criação. Utilizando-nos das palavras de Robert Stam (1981, p. 68), diriamos que Cópia fiel 
faz "a inserção de representações dentro de representações e o resultado dessa multiplicidade é nos forçar a refletir sobre a natureza da representação em si".

Há uma dificuldade inicial para detectarmos tal nivel de representação metalinguística, uma vez que não há nenhuma transição ou voz que informe explicitamente sobre os diferentes niveis de representação. Tal laconismo, aliado ao que Laura Mulvey denomina "Kiarostami's uncertainty principle", são responsáveis por saturar Cópia fiel de ambiguidade e polissemia. Em sua discussão da filmografia de Kiarostami, Mulvey (1998, p. 25) relaciona o princípio de incerteza ou indeterminação à atitude de curiosidade por parte do espectador: "[...] poder-se-ia quase dizer que o cinema de Kiarostami é 'sobre' curiosidade, diretamente engajando o espectador em um desejo de saber, decifrar e compreender". Para Mulvey (1998, p. 25), a curiosidade se dá em níveis diversos, que vão desde a curiosidade cultural - aquela de um estrangeiro que quer saber sobre o Irã contemporâneo - a uma curiosidade em termos narrativos (como a tentativa de dar sentido ao enigma materializado na tela) e cinematográficos (afinal, que cinema é esse, em termos de estilo e linguagem?). Embora Cópia fiel não se passe no Irã, e sim, na Itália, são perceptiveis os traços estilísticos do diretor no que diz respeito à indeterminação e à curiosidade de decifração, característicos de filmes anteriores.

\section{Diferentes níveis de Representação em CópIa FIEL}

Em sua releitura da questão da mimese em Aristóteles (1997) e em outros filósofos gregos, Luiz Costa Lima (2003, p. 79) ressalta o principio de que a mimese não pode ser vista como discurso exclusivo da arte. Nas palavras de Costa Lima (2003, p. 79): “Na arte, a mimesis apresenta apenas sua mais clara concretização, define apenas seu impulso básico: experimentar-se como outro para saber-se, nesta alteridade, a si mesmo". Essa reflexão, que sublinha o significado de mimese como "semelhante" e "outro" - poderiamos dizer, como "cópia" e "criação" - faz-se pertinente para a discussão de como a natureza mimética - quer no discurso artístico, quer nas representações sociais - engendra significados no filme Cópia fiel.

Comecemos com o significado de "cópia fiel", seguindo os índices que a narrativa vai oferecendo desde o início. Trata-se, inicialmente, de uma referência ao livro, intitulado Cópia fiel, do autor James Miller (William Shimell), assunto com que a narrativa filmica inicia. A questão é desdobrada no discurso que ele profere, com todas as referências à originalidade e à autenticidade no contexto artístico, e, em contraponto, à noção de cópia, reprodução, falsidade, mentira. O primeiro plano do filme - fixo, demorado e ao modo de uma moldura -, que mostra o livro a ser lançado e o microfone, já constitui, em certo sentido, um framework para o filme como um todo (que abordará a questão da arte e das representações e reproduções (cópias). Em determinado momento, a defesa da cópia é respaldada por possibilitar um retorno à origem, de modo a corroborar seu valor. James ressalta que a palavra originalidade e origem partilham a mesma etimologia - daí a articulação entre originalidade e nascimento; daí a sempre explorada relação cópia-original: uma relação que busca as fundações, as fontes, as origens. Um objeto original, ele explica, significa um objeto autêntico, genuíno, confiável, duradouro e que possui um valor intrínseco. É o que Walter Benjamin (1994, p. 170) chama de aura: "uma figura singular, composta de elementos espaciais e temporais: a aparição única de uma coisa distante, por mais perto que ela esteja". A 
aura, em sua singularidade, imbui-se de uma sacralidade característica dos objetos de culto e adoração. Na reflexão de Benjamin, a reprodutibilidade destrói a aura, e libera, portanto, o espectador, de um comportamento contemplativo (típico dos rituais de adoração) para uma tomada de atitude que ele denomina politi$c a$. Voltando à conferência que o autor do livro profere, um contra-argumento é oferecido: se a cópia é fiel, bem-feita, se o olhar de quem olha não vê diferença entre a cópia e o original, então não há razão, segundo o autor, para se atribuir valor superior a um (original) em detrimento do outro (cópia). O olhar do espectador atribui verdade ao que vê. Implicitamente, e de forma sofisticada, também é isso que Kiarostami faz: incita seu espectador a debruçar-se sobre uma "cópia fiel" (seu filme) que polissemicamente se multiplica em diversas camadas conotativas (não se constituindo, portanto, por tal principio de fidelidade).

A questão da "fidelidade da cópia" volta à tona, tempos depois, na narrativa, agora através de uma pintura - a Gioconda - que também tem o titulo de Cópia fiel. Durante 50 anos, acreditou-se que o quadro fosse original, mas, mesmo depois que a farsa foi descoberta, o quadro continuou atraindo o público, exatamente por sua perfeição, fidelidade e qualidade estética quanto à reprodução. Aliás, é por conta da relação entre o quadro e o livro (ambos intitulados Cópia fiel), que Elle (Juliette Binoche, dona de uma galeria) leva o autor James Miller até um museu; segundo ela, o quadro contempla questões discutidas em seu livro, portanto, poderia ter sido uma ilustração apropriada para a capa.

O fato é que a visita ao museu não entusiasmou James, embora ele tenha apreciado a oportunidade de conhecer o quadro. Sua apatia é evidente, a ponto de Elle questioná-lo a respeito. Ele explica que são muitos os exemplos de cópias e que essa pluralidade destitui, portanto, o valor paradigmático daquele quadro particular (embora tenha o mesmo título do seu livro). Em diálogo anterior, quando passeavam de carro, também fazem alusão às reproduções com a coca-cola (a exemplo das de Andy Warhol e Jasper Johns). Enfim, o filme faz proliferar referências a cópias e reproduções, aspecto que dota o significado de "cópia fiel", ainda no contexto artístico e cultural, de bastante ambiguidade e densidade.

Além da ambiguidade, algo que também chama a atenção, desde o início, no filme de Kiarostami, é a questão do laconismo. A narrativa vai deixando muita coisa por dizer, intencionalmente; diálogos são interrompidos, ora por ligações de telefones celulares (são vários os exemplos) ora pelo próprio rumo que os argumentos e perspectivas diferentes vão tomando. O laconismo certamente contribui para a elaboração da ambiguidade, que atinge um ponto máximo quando do encontro mais de perto entre James e Elle. Mas tanto o laconismo - intensificado pelas frequentes interrupções - quanto a ambiguidade também constituem indício de um ruído maior na (falta de) comunicação entre os dois. A propósito das conversas ao telefone, temos acesso às falas de Elle (diálogos com o filho), o que não acontece em relação a James. Trata-se de uma estratégia narrativa que a revela, enquanto ele fica na penumbra. Sem dúvida, um dado que adensa as estratégias de ambiguidade, indeterminação e laconismo é a utilização de várias línguas (italiano, inglês e francês) ao longo do filme.

O fato é que, para voltar aos vários sentidos do título (Cópia fiel), o filme desloca, de modo inovador, toda a discussão inicialmente inserida em contexto artístico - originalidade, reprodução - para também falar sobre o que é genuíno e verdadeiro no contexto das relações humanas. $\mathrm{E}$ isso é feito de modo tão diferente, com recursos tão indiretos, reveladores e tocantes que o filme continua a 
reverberar em nós após a sessão. Lembramo-nos novamente da afirmação de Laura Mulvey (1998, p. 25): “o desejo de saber e compreender do espectador é incrementado por um senso consciente da incerteza, inclusive sobre a verdade ou realidade daquilo que parece estar acontecendo". A própria origem do livro, segundo James, está ligada à observação de uma cena entre mãe e filho quando caminhavam, um à frente do outro, em Florença. De modo significativo, a descrição que ele dá coincide com o modo como nos são apresentados Elle e seu filho Julien, logo no início do filme. Elle se reconhece no relato e, ao ouvi-lo, chora. O espectador também faz a conexão entre as duas cenas, que produzem um paralelismo visual (embora a cena do relato de James, sobre a mãe e o filho em Florença, seja apenas verbalizada, podendo apenas ser imaginada por nós).

A partir daí, aquele autor e aquela dona de galeria de arte são sujeitos que conversam tão intimamente e profundamente sobre relacionamentos humanos, que o filme parece ter deixado seu fio narrativo condutor de lado (a questão metalinguística das cópias) e tomado outro rumo. No entanto, trata-se da possibilidade de trabalhar com outros sentidos incorporados ao universo da "cópia fiel". $\mathrm{Na}$ verdade, esse aspecto já havia sido antecipado quando James cita um leitor que havia considerado o assunto do seu livro também como um convite à autoanálise, possibilidade de melhor entendimento do ser. Em outro exemplo, Elle diz que o filho Julien é a "cópia fiel" do pai - só faz o que quer. E todo o evolver da relação entre James e Elle, durante o passeio, revela que ela também vê nele uma semelhança (cópia) com seu companheiro (o outro ausente).

O deslocamento da questão da representação, do contexto artístico para o contexto da subjetividade das relações, ganha contornos específicos quando o olhar do outro incide sobre esse casal. A partir desse ponto, cria-se um jogo intricado entre quem eles são e como são vistos pelo olhar de fora, dos outros; trata-se de um jogo que ilustra, de forma eloquente, o fato de que "a sociedade respira e transpira representações" (COSTA LIMA, 2003, p. 89). Na verdade, o passeio dos dois é todo permeado por encontros com outros, que os tomam por marido e mulher. A questão do casamento e das relações familiares já é valorizada pelo local (Lucignano) onde Elle leva James - um lugar para onde vão os noivos fazer fotos e pedir à árvore dourada sorte e bênção para o casamento. James cita o poema "The garden of leaflessness", que descreve a mudança que ocorre com as próprias estações - a exemplo da primavera, que não dura para sempre. Com isso, ele cria uma relação metafórica com as relações amorosas, que devem sempre estar vigilantes em relação a dois aspectos: cuidado e consciência. Nesse local, chama a atenção o colírio colocado nos olhos de uma noiva, para fingir emoção; também a verdade desoladora de outra, que explicitava no rosto o desconsolo com o casamento. Aqui, Elle também "mente" aos noivos, ao dizer que James é seu marido, que são felizes, casados há 15 anos, e que vieram ali para celebrar. A recusa dele em tirar a foto dá bem a medida de sua recusa em entrar no jogo. A questão da fotografia, ainda mais por ser mediada pelo colírio, pela pose, também amplifica e acentua a problemática da representação.

Sim, ali é dificil saber o que é verdade, o que é encenação. A perambulação dos dois - que se revelam, de modo divergente, em seus diálogos - vai se justapondo a casais de noivos, a cenas de celebração, danças, que não estão ali apenas por fazerem parte da mitologia do lugar, mas são intencionalmente enquadradas, daquele modo, com o intuito de oferecer um contraponto para o significado do diálogo entre os dois, suas visões acerca das relações, da convi- 
vência a dois, da educação dos filhos. As justaposições estão a serviço da ironia, que oferece, implicitamente, outro discurso - um discurso que solapa a celebração, e antecipa, como se num pressentimento, a efemeridade da festa.

Exemplifiquemos com o efeito do olhar do outro sobre eles, referido acima. Dois casos são emblemáticos: primeiro, a senhora do restaurante, que os toma por marido e mulher, e lhe dá todos aqueles conselhos sobre aceitação e resignação, dizendo que é bem melhor que a mulher tenha o trabalho do marido (em vez de outra mulher) como rival. Elle, por outro lado, retruca, e diz que não casou para viver sozinha. A senhora também sussurra algo, a que não temos acesso, em seu ouvido. Quando James, que estava falando ao celular do lado de fora, retorna, Elle lhe explica que a senhora inferiu que eles são casados, e que ela não desmentiu. Ao que ele responde: "Bem, formamos um belo casal". Para o espectador, é inevitável a questão: será que eles estão resgatando alguma relação anterior ou é tudo representação? O fato é que, aos olhos da dona do restaurante, eles formam um belo casal. E se Elle não desmentiu a mulher, a encenação é incorporada e legitimada pelo comportamento dos dois.

A interpretação da mulher do restaurante sobre eles encontra paralelismo, ao tempo em que vai sendo aprofundada, no encontro posterior que eles têm com um casal já maduro, na praça da estátua. Aqui, é a estátua/escultura de um casal, situada no meio da praça, com a mulher descansando a cabeça no ombro do homem (de novo, o tema união/casamento; de novo, a representação de um casal; de novo, um objeto artístico), que detona toda a tensão. Percebemos que enquanto Elle imediatamente (e pelo avesso) se identifica com o gesto - afinal, a ela lhe falta esse ombro - James insiste na consciência de que cada um é só, e, no final, cada um vive sua própria vida. Aqui, a própria Elle refere-se a James como seu marido. E o senhor com quem conversam dá um conselho a James: diz que a única coisa de que Elle precisa, naquele momento, é que ele coloque sua mão sobre seu ombro. E é assim, depois que se despedem do casal, que James e Elle, feito casal (verdade, representação?), entram em outro restaurante. Esses exemplos demonstram as relações simétricas entre arte e vida e também entre arte e arte ao longo do filme.

E o que passamos a assistir (o verbo é intencional), a partir desse momento, é uma encenação explícita entre os dois. É como se - sem transição alguma, sem nenhum aviso - passássemos a testemunhar a intimidade dolorosa daquele casal, a derrocada e decadência de seu relacionamento. A propósito, alguns observam, em Cópia fiel, um intertexto com Romance na Itália, de Rossellini ${ }^{1}$, filme sobre a desintegração de um casal; essa ligação intertextual dota o título de Kiarostami de significado irônico. Afinal, ainda que ele tome determinados aspectos do filme de Rossellini como referentes, seu filme não é uma reprodução fidedigna daquele. Em Rossellini, não há ambiguidade quanto à relação em crise do casal - tal aspecto é verbalizado através de diálogos e demonstrado pelo comportamento de animosidade de um em relação ao outro. Não podemos deixar de observar, porém, certo diálogo entre os filmes - os passeios de carro, as visitas a galerias de arte, a monumentos a céu aberto e as constantes discordâncias e reclamações entre o casal são recorrentes nos dois filmes. Em Viagem na Itália, é bastante evidente a questão da maternidade - são várias as cenas em que a Sra. Joyce observa mães grávidas ou

Em Caminhos de Kiarostami, Jean-Claude Bernardet (2004) faz referência às ressonâncias de Rossellini na filmografia de Kiarostami, sobretudo quanto à presença do carro e seus percursos e viagens. 
mães passeando com seus filhos. Há um momento, inclusive, em que ela justifica o fracasso da relação pela ausência de filho. Essa questão - relação entre pais e filhos - também aparece de modo contundente em Cópia fiel, sobretudo através da relação entre Elle e seu filho, algo representado em camadas diversas ao longo do filme. Vendo os dois filmes, não é dificil notar que ambos os cineastas, Rossellini e Kiarostami, fazem uso bastante criativo da articulação entre subjetividade dos personagens e ambientação ou mise en scène. Os espaços ascendem metaforicamente na medida em que contribuem para revelar os sujeitos. Em ambos os filmes, também permeia uma atmosfera substancial de efemeridade, algo que se contrapõe aos sentidos de permanência dos monumentos artísticos dos lugares. É como se tal contraste nos dissesse: a arte é longa; a vida é breve.

Voltemos à sequência de Cópia fiel, introduzida e interrompida acima. Percebemos claramente a mudança de tonalidade estética na sequência toda, que se constrói de forma deliberadamente estilizada, em que James tem a voz mais alta (empostada, até porque, agora, fala italiano), e não sente pudor de revelar impaciência (inclusive com o garçom); há, ao longo do diálogo, reclamação e cobrança de um em relação ao outro. Até a crítica à convenção (fingimento) que envolve a degustação do vinho entra, significativamente, no nível de reflexão. Sua transformação, em termos emocionais, e a utilização do italiano parecem dizer que sentimento e língua andam de mãos dadas. Os arroubos da intimidade se expressam melhor em uma língua mais melódica, expansiva e emotiva.

É também relevante o momento anterior quando Elle vai ao banheiro passar batom e colocar os brincos. Qual o significado do batom, dos brincos? Como interferem na nossa apreensão de Elle? Que efeito provocaram em James, na sua visão de Elle, como mulher? Ela volta e ele não faz nenhum comentário. Que mulher já não reclamou da falta de atenção do companheiro, por não notar seu corte de cabelo, sua roupa, seu perfume? De que modo o batom e os brincos aprofundam, porque revelam, inclusive metalinguisticamente, o teor da brincadeira, do faz de conta? Ou acentuam a impotência de sedução dela? Por que Elle quer ser outra? Ou será que ela quer realçar um lado já seu, mas adormecido?

Claramente, essa mudança na personagem instaura um deslocamento do nivel do discurso verbal - diálogos, argumentação - para o nível da aparência física, do corpo, da sexualidade. De modo surpreendente, também a retirada do sutiã na igreja, tempos depois, faz referência ao corpo, assunto que será depois detalhado no quarto de hotel. Afinal, o que oprime Elle? Do que mesmo ela quer se aliviar? Será que é mesmo a James que ela fala, ou a um outro, cujo lugar, naquele momento, ele ocupa? Todos esses exemplos contêm índices que revelam uma "coloração simbólica" (COSTA LIMA, 2003, p. 88) característica das representações sociais entre os sujeitos:

O corpo não se torna simbólico no ritual; o ritual apenas condensa um investimento que se cumpre diariamente. É a maneira de andar, de mover a cabeça, de cruzar as pernas, de olhar, o modo como o próprio corpo cheira que são objetos imediatos de investimento simbólico (COSTA LIMA, 2003, p. 88).

Tomando essa afirmação como embasamento, são vários os exemplos no filme em que o corpo e a gestualidade indiciam significados que, gradativamente, vão se relacionando e ecoando entre si; os exemplos já referidos, quanto ao modo de caminhar de Elle e seu filho (que repete o gesto da mãe e do filho no relato de James; também na recriação do gesto em seu livro); o gesto da mão sobre o om- 
bro/da cabeça sobre o ombro (gesto representado na escultura/gesto repetido entre James e Elle); o batom, os brincos, a retirada do sutiã, todos são investidos de sentidos para além do meramente referencial, acrescentando, metaforicamente, à caracterização de Elle como sujeito feminino.

O diálogo entre os dois no restaurante expõe o fracasso da relação - vinho ruim, reclamações sobre a noite anterior (sono/ronco em vez de sexo; ausência de aconchego amoroso). No entanto, ainda restam os dois pedaços de pão, que ela, gentilmente e solidariamente, lhe dá, quando saem (em momentos diferentes) do restaurante. O pão também é imbuído de significado simbólico, remetendo, ao mesmo tempo, ao rotineiro e ordinário ("pão nosso de cada dia"), mas também à partilha quanto à resistência. É preciso compartilhar o pão do dia a dia, que metonimicamente constitui um casamento. Porém, de novo, há dissonância: um caminha à frente do outro. O vinho e o pão, vistos como signos, em vez de rimarem com comunhão, se alinham ironicamente com ruptura.

De modo revelador, o casal de velhinhos que sai da igreja, um ao lado do outro, um apoiando o outro, oferece mais um contraponto à história (verdadeira, fake, máscara?) de James e Elle. Quando sentam nos degraus, Elle recosta seu ombro sobre o de James (gesto repetido e alusivo ao casal da escultura) e beija seu pescoço. A visão que temos dos dois na tela é dividida com a visão que temos do casal de velhinhos. E quando James e Elle estão lá em cima, no quarto do hotel, ela tenta reavivar a memória dele, que diz não ter nenhuma lembrança. O cheiro no travesseiro, as janelas, cujas visões falam tão eloquentemente a Elle, nada dizem a ele. De novo, a situação nos diz, conotativamente, que há ao menos dois finais para os casais: podem terminar como (os) velhinhos, um ao lado do outro, em consonância e harmonia, com apoio mútuo (no filme de Rossellini, em que temos o final feliz com a reconciliação do casal, há essa expectativa); ou podem terminar como James e Elle (ou remetendo àquilo que representam), em desacordo, tendo lembranças diferentes, memória afetiva distinta, sem nenhuma sintonia.

\section{CONSIDERAÇÕES FINAIS}

Em sua discussão sobre a metaficção - ou aquilo que denomina "narrativa narcisista" -, Linda Hutcheon (1991, p. 18) responde aos críticos que veem nas narrativas autorreflexivas uma falta de sensibilidade ou preocupação humanitária. Embora o contexto de Hutcheon advenha da literatura (e não do cinema), podemos cooptar seu argumento para a presente discussão e tentar compreender por que determinados artistas (escritores, cineastas), a exemplo de Kiarostami, fazem uso das propriedades formais da ficção como matéria para suas narrativas.

Como tentamos demonstrar ao longo da presente discussão, Kiarostami parte da articulação entre representação, original e cópia no contexto artístico - em que questões ligadas a fidelidade, valor e aura possuem relevância - para também considerar questões de representação nas relações humanas, afetivas e sociais, através de microencenações que simulam conflitos conjugais e embates na relação entre pais e filhos. Desse modo, ao considerar diferentes significados de mimese e embaralhar niveis distintos de "realidade" e "fantasia"; ao investir em estratégias estilísticas como incerteza, indeterminação e laconismo, de um lado, e repetição e paralelismo, de outro; ao chamar a atenção para gestos repetidos, para o modo como lemos aquilo que vemos, Cópia fiel desafia noções tra- 
dicionais de realismo e verossimilhança, e desorienta o espectador em suas expectativas; ao fazê-lo, conclama a cumplicidade do espectador no desnudamento das convenções narrativas, exigindo do mesmo uma atitude de abertura para novos códigos e inesperados arranjos (meta)ficcionais.

\section{Auto-reflexivity in Certified copy, by Abbas Kiarostami}

Abstract: Our aim is to discuss the film Certified copy, by Abbas Kiarostami, by initially observing some premises: the narrative ambiguously articulates semantic nuances of the expression "faithful copy" in terms of both artistic and human relations; the narrative substantially invests in stylistic strategies, as, for instance, laconism, discontinuity, and parallelism, which endow the story with uncertainty, indetermination and ambiguity. The film displaces the notions of authenticity and copy from the artistic context (mimesis) to that of human subjectivity, and, by doing that, it surprises, challenges and de-stabilizes the spectator in his/her attempt at interpretation. In Certified copy, because of the metafictional game, we are all the time induced to reflect critically, so as to take aesthetic advantage of what is not shown and said but has fundamental relevance in the film's significance.

Keywords: Mimesis. Ambiguity. Metafiction.

\section{REFERÊNCIAS}

ARISTÓTElES. A poética clássica. Tradução Jaime Bruna. São Paulo: Cultrix, 1997.

BENJAMIN, W. A obra de arte na era de sua reprodutibilidade técnica. In: BENJAMIN, W. Magia e técnica, arte e politica. Ensaios sobre literatura e história da cultura. Tradução Sérgio Paulo Rouanet. São Paulo: Brasiliense, 1994.

BERNARDET, J.-C. Caminhos de Kiarostami. São Paulo: Companhia das Letras, 2004.

COSTA LIMA, L. Mimesis e modernidade: formas das sombras. São Paulo: Paz e Terra, 2003.

HUTCHEON, L. Narcissistic narrative: the metafictional paradox. London: Routledge, 1991.

MULVEY, L. Kiarostami's uncertainty principle. Sight and sound, v. 8, n. 6, p. 24-27, June 1998.

STAM, R. O espetáculo interrompido: literatura e cinema de desmistificação. Tradução José Eduardo Moretzsohn. Rio de Janeiro: Paz e Terra, 1981.

WAUGH, P. Metafiction: the theory and practice of self-conscious fiction. London: New York: Routledge, 1984.

Recebido em novembro de 2016.

Aprovado em fevereiro de 2017. 